\title{
EXPLORAÇÃO MINERAL NA AMAZÔNIA BRASILEIRA: RELAÇÕES DE TRABALHO E MIGRAÇÃO INTERNA NO MUNICÍPIO DE PEDRA BRANCA DO AMAPARI-AP
}

\section{ARTIGO ORIGINAL}

SOUZA, Keulle Oliveira da ${ }^{1}$

TRINDADE, Gleice Tavares ${ }^{2}$

FECURY, Amanda Alves ${ }^{3}$

DIAS, Cláudio Gellis de Mattos ${ }^{4}$

MOREIRA, Elisângela Claudia de Medeiros ${ }^{5}$

DENDASCK, Carla Viana ${ }^{6}$

\footnotetext{
${ }^{1}$ Mestranda em Estudos Antrópicos na Amazônia-PPGEAA, na Universidade Federal do Pará-UFPA, Campus Castanhal.

${ }^{2}$ Graduação em Ciências Sociais. Docente da rede de Ensino do Estado do Amapá.

${ }^{3}$ Doutora em Doenças Tropicais. Docente e Pesquisadora da Universidade Federal do Amapá-UNIFAP. Pesquisadora Colaboradora do Núcleo de Medicina Tropical da UFPA-NMT/UFPA.

${ }^{4}$ Doutor em Teoria e Pesquisa do Comportamento. Docente e Pesquisador do Instituto Federal do Amapá-IFAP.

${ }^{5}$ Mestre em Teoria e Pesquisa do Comportamento. Docente da Universidade do Estado do Pará-UEPA. Doutoranda em Doenças Tropicais na Universidade Federal do Pará- NMT/UFPA.

${ }^{6}$ Teóloga. Doutora em Psicanálise Clínica. Pesquisadora do Centro de Pesquisa e Estudos Avançados, São Paulo, SP.
} 
FERNANDES, José Guilherme dos Santos ${ }^{7}$

PIRES, Yomara Pinheiro ${ }^{8}$

PINTO, Manoel de Jesus de Souza ${ }^{9}$

OLIVEIRA, Euzébio de ${ }^{10}$

SOUZA, Keulle Oliveira da. Et al. Exploração mineral na Amazônia brasileira: Relações de trabalho e migração interna no Município de Pedra Branca do Amapari-AP. Revista Científica Multidisciplinar Núcleo do Conhecimento. Ano 04, Ed. 12, Vol. 08, pp. 05-28. Dezembro de 2019. ISSN: 2448-0959, Link de acesso: https://www.nucleodoconhecimento.com.br/meio-ambiente/exploracaomineral

\section{RESUMO}

O presente artigo consiste numa análise das consequências sociais e econômicas que o novo ciclo de mineração desencadeado no estado do Amapá gerou e está gerando para o município de Pedra Branca do Amapari (PBA). Especificamente, o processo de migração e as novas relações de trabalho estabelecidas na cidade como efeitos causados pela atividade de exploração de minério em PBA. Para tanto, partiu-se do ponto de análise que a exploração mineral em PBA é integrante do processo de

${ }^{7}$ Doutor em Letras. Docente e Pesquisador na Universidade Federal do Pará-UFPA, Campus Castanhal.

${ }^{8}$ Doutora em Engenharia Elétrica. Docente e Pesquisadora na Universidade Federal do Pará-UFPA, Campus Castanhal.

${ }^{9}$ Doutor em Desenvolvimento Sustentável do Trópico Úmido. Docente e Pesquisador da Universidade Federal do Amapá-UNIFAP.

10 Doutor em Medicina/Doenças Tropicais. Docente e Pesquisador na Universidade Federal do Pará-UFPA. Pesquisador Colaborador do Núcleo de Medicina Tropical NMT/UFPA. 
ocupação e exploração regional da Amazônia e que, portanto, não pode ser analisado somente do ponto de vista do contexto histórico, social e econômico amapaense, mas como parte do processo de colonização histórica da região que seguiu, ao longo dos séculos, diferentes modelos econômicos e formas de intervenção.

Palavras-chaves: Mineração, migração, relações de trabalho, Pedra Branca do Amapari, Amazônia.

\section{INTRODUÇÃO}

"A história do Amapá se confunde com a exploração mineral no estado, uma vez que o Território Federal do Amapá foi criado em 1943 e, em 1946, é descoberta uma jazida de manganês em Serra do Navio" (BARBOSA, 2011, p. 8). Na década de 80, o foco mineral se volta para o município de Calçoene com a exploração de ouro na cidade. Nos anos 90, são Mazagão e Vitória do Jari que desta vez tornam-se alvo da atividade mineral com a exploração de ouro e caulim, respectivamente. E, mais adiante, no ano de 2004, as atenções voltam-se para Pedra Branca do Amapari com a exploração de ouro e ferro no município (BARBOSA, 2011).

Desse modo, o presente trabalho analisou as consequências sociais e econômicas que o novo ciclo de mineração desencadeado no Estado do Amapá, pertencente a região da Amazônia brasileira gerou e ainda está gerando, para o município de Pedra Branca do Amapari (PBA). Mais especificamente, o processo de migração e as novas relações de trabalho estabelecidas na cidade, como efeitos causados pela atividade de exploração de minério em PBA.

Para tanto, partimos do ponto de análise que a exploração mineral em PBA é integrante do processo de ocupação e exploração regional da Amazônia e que, portanto, não pode ser analisado somente do ponto de vista do contexto histórico, social e econômico amapaense, mas como parte do processo de colonização histórica da região que seguiu, ao longo dos séculos, diferentes modelos econômicos e formas de intervenção, mas com uma característica comum: "a ocupação se fez 
invariavelmente e ainda hoje se faz a partir de iniciativas externas". (BECKER, 2001, p.135)

Portanto, afirmamos que o ponto chave deste trabalho encontra-se nos dois principais efeitos do processo de exploração de recursos naturais na Amazônia e que se interligam à medida que fazem parte de um mesmo fenômeno, o de expansão física do capital. Como consequência, ocorrem os deslocamentos populacionais e o estabelecimento de uma nova dinâmica no mundo do trabalho a nível regional. Vale destacar que este processo obedece a um realinhamento histórico do papel que a Amazônia possui para o capital privado, sobretudo o internacional.

Atualmente, essa exploração é marcada pela presença do capital externo, com grandes investimentos no setor energético, mineral, madeireiro e metalúrgico, com o objetivo de produzir basicamente commodities primárias para a exportação. Em PBA, a exploração do minério também vem seguindo essa lógica, uma vez que a maioria da produção gerada do município é também para exportação para o mercado internacional.

Os processos de ocupação regional, historicamente vieram seguidos de grandes fluxos migratórios e pela alteração, em parte, nas relações de trabalho da região, graças à demanda de força de trabalho gerada em processos assim. Realidade que foi também por nós observada em Pedra Branca do Amapari. Nos últimos anos, a cidade sofreu um surto populacional ocasionado pela realização de atividades minerais no município que, em processos como esse, funcionam como causa de atração de deslocamentos populacionais.

Desse modo, analisamos os efeitos sociais da mineração no município a partir dos impactos no desenvolvimento regional como também realizamos uma breve contextualização dos problemas urbanos gerados pelo crescimento populacional e ocupação territorial desornada, a partir da dinâmica de ocupação e exploração na Amazônia, trazendo-a para o contexto amapaense. 
Assim, dividimos o presente em quatro partes para um melhor desenvolvimento da discussão. A primeira faz uma breve contextualização do município que foi escolhido como nosso objeto de estudo. A segunda faz uma abordagem sintética do processo histórico de ocupação e exploração da Amazônia. A terceira parte analisa a cidade de Pedra Branca, o seu aumento populacional e as relações de trabalho dentro deste contexto regional de exploração amazônica e na quarta fazemos abordamos os resultados da pesquisa de campo, que foi realizado pelo método observacional.

\section{PEDRA BRANCA DO AMAPARI: UMA BREVE CONTEXTUALIZAÇÃO}

Apesar de ser oficialmente criado somente em 1992, Pedra Branca do Amapari possui um longo histórico. Na região, são encontrados registros da exploração de ouro desde 1935 quando, nessa época, havia abundância do metal e a exploração se dava de forma artesanal por garimpeiros. Nesse período,

Cerca de 500 a 600 faiscadores exploravam o rio. Em 1938, o número de exploradores do minério já chegava à casa de 5.000 pessoas, algumas buscando novos igarapés para extrair 0 ouro, outras caminhando para o local de extração dos que tinham chegado na frente, outras, por fim, apenas sugando o suor dos que trabalhavam, vendendo mercadorias a preços elevadíssimos (SECRETARIA DE MEIO AMBIENTE de PBA, 2013, p. 01).

Porém, "em 1940, a produção decrescera e a maioria da população começou a ser dispersar" (SECRETARIA DE MEIO AMBIENTE de PBA, 2013, p. 01). A partir de 1950, começam a surgir os primeiros moradores da vila de Pedra Branca, motivados pela descoberta de manganês no município vizinho, que fica a cerca de $20 \mathrm{~km}$ de PBA, Serra do Navio.

Com a implantação do projeto de mineração pela Indústria e Comércio de Minérios S.A. (ICOMI), para a exploração das jazidas de manganês de Serra do Navio, o acesso à região foi facilitado através da construção da estrada de ferro do Amapá (EFA), responsável pela interligação do município ao Porto de Santana para a escoação do minério (Figura 1). Com isso, famílias foram migrando para a região, 
principalmente, em busca de oportunidades de emprego na ICOMI, mas também em busca de ouro nos garimpos e de terras visando o cultivo agroalimentar, especialmente por aquelas vindas do nordeste. Porém, a cidade não se beneficia diretamente dessa exploração e não é contemplada com a política de urbanização que foi desenvolvida em Serra do Navio (BARBOSA, 2011).

Figura 1: Homens trabalhando no início da construção da Estrada de Ferro do Amapá - EFA

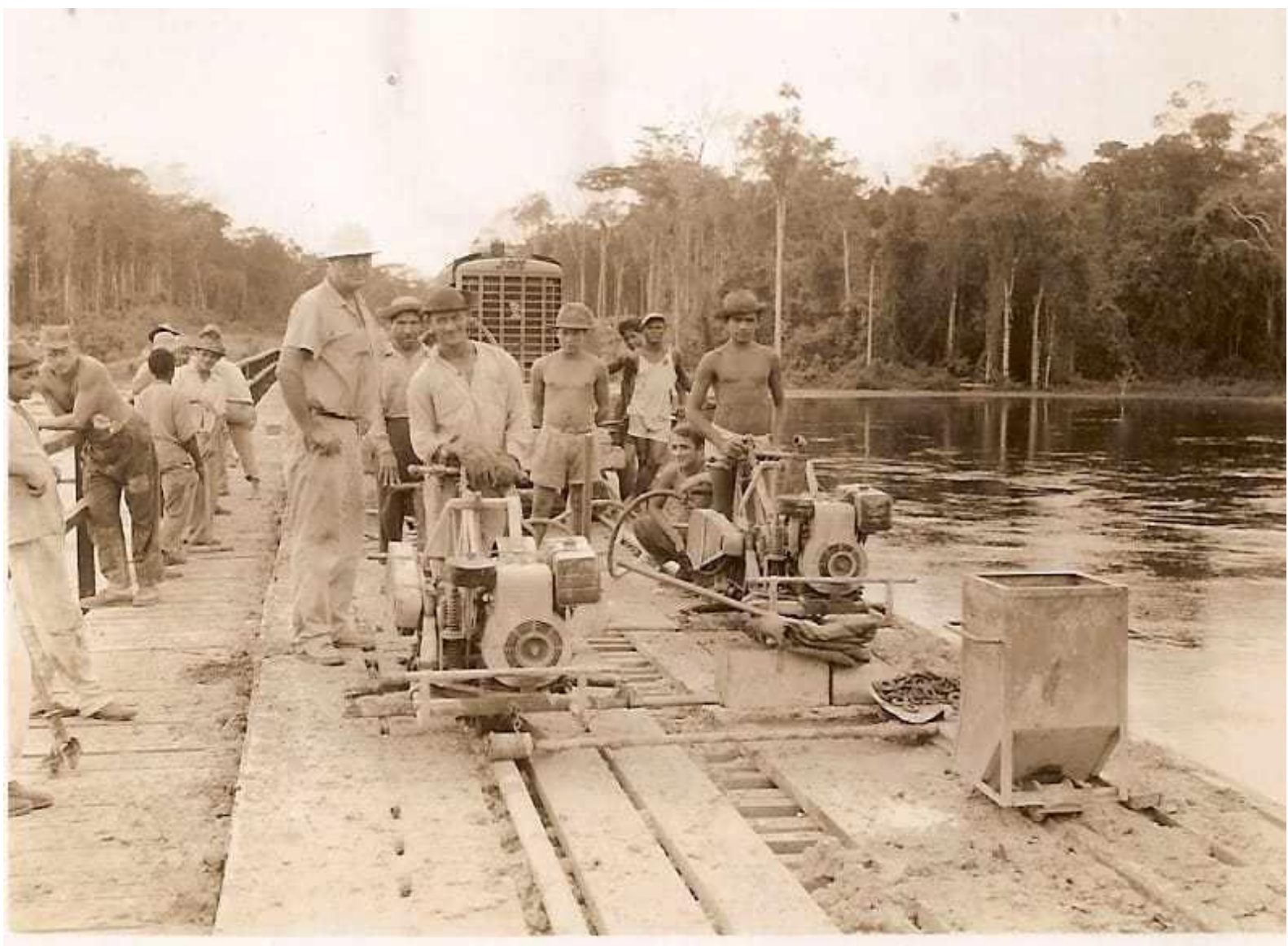

Fonte: Secretaria de Meio Ambiente de Pedra Branca do Amapari.

Até 1992, Pedra Branca seguiu sendo apenas uma pequena vila de moradores, que viviam basicamente da agricultura e da garimpagem do ouro. A partir de então, o município é oficialmente criado e com isso adquirindo nova dinâmica social, já que agora havia a necessidade de funcionamento de uma estrutura político-administrativa na cidade. No entanto, PBA seguiu sendo política e economicamente, de baixa 
relevância para o estado, situação que começa a alterar-se significativamente a partir de 2004 com "o prenúncio de pesquisas na área e das instalações das mineradoras" (RIBEIRO; SILVA, 2010, p. 21). A partir de então, "o núcleo urbano do município foi palco de movimentos migratórios acelerados em busca de emprego e consequentemente melhorias de vida" (Idem).

Com a exploração de ouro e posteriormente do ferro, por meio da Mineração em Pedra Branca do Amapari (MPBA), também foi aumentando a circulação de mercadorias e, consequentemente, a arrecadação tributária do município. Além disso, a cidade também arrecada os royalties que passou a receber das empresas exploradoras de minério que atuam em PBA, tendo assim um aumento relevante da sua receita.

Entretanto, os impactos da exploração mineral para o município não são somente financeiros. Com a instalação de empreendimentos minerais na cidade, ocorre também uma mudança radical na sua configuração social, política e urbana. A cidade sofreu o maior aumento populacional do estado do Amapá nos últimos anos. De acordo com o último censo demográfico do IBGE, Pedra Branca possui cerca de 10.773 habitantes (IBGE, 2010). Se comparado ao censo anterior, do ano de 2000, quando a cidade possuía apenas 4.009 habitantes, PBA teve um aumento populacional de 168,72\% em dez anos, e ainda estimasse que até o final de 2019 a população atinja um total de 16.502 pessoas, obtendo uma taxa de crescimento populacional superior, inclusive, a do próprio Estado.

Todavia, seu crescimento populacional não veio acompanhado de planejamento, o que acarretou no surgimento de problemas urbanos e sociais e no agravamento dos já existentes, como falta de saneamento básico, ausência de política de mobilidade urbana, deficiência no serviço de coleta e limpeza do lixo, etc., todas consequências do crescimento desordenado da cidade, influenciados pelo fluxo intenso de migração para o município.

Como todo lugar em que ocorre a explosão demográfica, oriunda de atividades econômicas sazonais e sem planejamento, PBA sofreu e sofre com a força migratória decorrente da presença de dinâmicas sociais que põem em confronto visões 
diferenciadas acerca das práticas e valores quando consideramos a importância do espaço para seus usuários. Isto porque quase sempre processos migratórios tocados por razões de trabalho transformam o ambiente e são o leit-motive para confrontos entre os locais e os chegados, sendo a categoria trabalho importante para pensarmos a "migração como um processo social e os migrantes como agentes desse processo" (SILVA, 2005, p. 54). Ou seja, o fato de a avalanche demográfica ter se intensificado em PBA decorreu do processo migratório de trabalho, a busca pelo enriquecimento, que fez com que a população local tivesse um acréscimo de quase $200 \%$, o que gerou um novo processo social eivado de conflitos e de impactos socioambientais ocasionados por essa nova antropização. Daí ser importante sabermos detidamente sobre as narrativas migrantes, que não estão nos documentos, pois que essa elevada migração em PBA aparece apenas como dados "sem caras", sendo necessária a escuta atenta dos agentes dessa migração, pois que "a narrativa migrante é marca do sujeito em movência para fora de sua experiência aborígine, situado em uma nova localidade e territorialidade que se desloca nos interstícios da sociedade" (FERNANDES, 2006, p.163).

Em verdade, PBA vem a ser um dos vários índices na Amazônia brasileira em que a exploração mineral é sinônimo de devastação ambiental e desigualdades sociais e decadência civilizatória, o que observaremos com mais destaque a seguir.

\section{EXPLORAÇÃO MINERAL, RELAÇÕES DE TRABALHO E MIGRAÇÃO INTERNA NA AMAZÔNIA BRASILEIRA}

Para fins de análise, neste artigo avaliaremos o processo de exploração mineral desencadeado mais recentemente no município de Pedra Branca do Amapari e, a partir de então, o seu intenso fluxo migratório e a nova dinâmica das relações de trabalho na cidade, a partir de uma visão geral sobre a dinâmica de exploração mineral na Amazônia e seus efeitos, relacionado ao processo de ocupação histórica da região, levando em consideração o processo em questão em PBA como parte integrante deste contexto regional amazônico. 
A Amazônia, em sua história, tem sido alvo de grandes intervenções econômicas, isso se deve à importância que ela possui para o capital, sobretudo, internacional. Não por acaso que a "sua ocupação se fez em surtos devassadores ligados à valorização momentânea de produtos no mercado internacional, seguidos de longos períodos de estagnação" (BECKER, 2001, p. 135).

Historicamente, nesses processos de intervenções seguiram-se diferentes modelos de ocupação e desenvolvimento econômico, tais como, as drogas do sertão, o ciclo da borracha, e mais recentemente, os grandes projetos agropecuários e minerais que causaram mudanças significativas na região, principalmente influenciando na sua reestruturação sócio espacial através de fluxos migratórios, formação de novos núcleos urbanos e com a criação de infraestrutura básica em setores estratégicos para o desenvolvimento e a produção capitalista como o setor de energia, portuário e de transportes terrestre (ferrovias, estradas), por exemplo, necessária ao modelo de exploração que vigora de forma consolidada desde a década de 70 (RIBEIRO; SILVA, 2010).

O processo de exploração mineral de modo industrial na Amazônia teve início ainda à época do então Território Federal do Amapá, quando a exploração do minério de manganês do município de Serra do Navio-AP representou a constituição do primeiro grande empreendimento mineral na região, como afirma Monteiro:

Tal mina foi edificada em uma conjuntura marcada pelo estabelecimento, em termos nacionais, de um novo regime político e pela reorientação das relações estabelecidas entre o Estado e a economia. Era o fim da ditadura de Getúlio Vargas e a nova Constituição, promulgada em 1946, em substituição à Carta de 1937, estava fortemente inspirada em princípios do liberalismo econômico (MONTEIRO, 2005, p. 187).

Desse modo iniciou na Amazônia o primeiro grande processo de exploração mineral da região, realizado pela empresa então denominada Indústria e Comércio de Minérios Sociedade Anônima (ICOMI S.A), que iniciou em 1950 e durou por volta de 40 anos. 
Assim, a extração de minério de manganês foi, por cerca de duas décadas, a única significativa extração mineral industrial na Amazônia brasileira, contexto que começa a alterar-se substancialmente a partir do golpe militar de 1964 no Brasil. A partir de então, se estabelece uma nova política nacional de ocupação regional, que se consolida na década de 70, baseada na visão da necessidade imperiosa de ocupar territorialmente a região. "A ditadura militar dá ao processo de ocupação o significado de uma expansão do grande capital sobre uma área ainda não explorada em seus recursos naturais" (FERREIRA; CASTRO, 2009, p. 07). Esta nova política pressupunha a sua ocupação combinada com a exploração, através de grandes projetos, de suas conhecidas riquezas, entre elas, as minerais, como afirma Becker:

A partir de 1968, mecanismos fiscais e creditícios subsidiaram o fluxo de capital do Sudeste e do exterior para a região, através de bancos oficiais, particularmente, o Banco da Amazônia S. A. (Basa). Por outro lado, induziu-se a migração através de múltiplos mecanismos, inclusive projetos de colonização, visando ao povoamento e a formação de um mercado de mão-de obra local (BECKER, 2001, p. 138).

No entanto, a região possuía - e ainda possui - enormes obstáculos físicos para a sua ocupação/exploração. Daí a articulação do próprio governo de políticas de desenvolvimento para Amazônia que priorizavam sobretudo, interesses do capital privado, visando atrair investimentos para a região.

Nesse sentido, em 1974, o governo criou então os Polos Agropecuários e Agrominerais da Amazônia - Polamazônia, objetivando gerar polos de desenvolvimento na região, principalmente por meio de grandes projetos de exploração mineral.

No 'polo do Amapá', a política de incentivos fiscais foi utilizada pela Icomi para implantar uma usina de pelotização, (...). Naquele 'polo' também entrou em operação a primeira empresa dedicada à extração industrial de caulim na Amazônia. Tratava-se da Caulim da Amazônia (Cadam), criada como parte dos investimentos do milionário norte-americano Daniel Ludwig na área da Jari florestal (MONTEIRO, 2005, p. 188).

Além dos incentivos fiscais e creditícios dados pelo governo brasileiro, ele também precisou viabilizar a infraestrutura básica para a operação desses projetos, tais como 
estradas, ferrovias, portos, etc. para a exploração, não somente mineral, dos recursos naturais da região. A partir de então, efetivaram-se "redes de circulação e de telecomunicação, por onde passaram a se mobilizar os novos fluxos de mão-de-obra, capital e informação" (BECKER, 2001, p. 139).

Porém, o governo enfrentou dificuldades com o financiamento das obras de infraestrutura. Desse modo,

Como o Governo Federal tinha necessidade de agilizar a instalação e o início da operação dos projetos minero-metalúrgicos, criou, em 1980, o Programa Grande Carajás (PGC). Uma tentativa de coordenar a execução de projetos já existentes na área (especialmente o Projeto Ferro Carajás, a Albras, a Alunorte, a Alumar e a Usina de Tucuruí) e de concentrar ainda mais os recursos estatais e os oriundos de incentivos fiscais e creditícios (MONTEIRO, 2005, p. 190).

Nesse contexto de atração de investimentos para a região, veio então a instalação de grandes projetos minerais e como consequência destes, uma série de efeitos sociais para a Amazônia. Entre elas, a que nos interessa mais diretamente neste artigo, a dinâmica das relações de trabalho e o processo de migração na Amazônia.

Os investimentos do capital privado e nacional; a viabilização de infraestrutura na região; e a instalação de grandes projetos de mineração[1], foram responsáveis, em parte, pela atração de determinado contingente populacional e por alterações na dinâmica das relações de trabalho regional. "A expansão populacional pós década de 60 em direção a novos territórios (...) configurou um novo mapa do Brasil. A fronteira para o aporte de investimentos, políticas e população 'marchou' em direção à Amazônia" (MENEZES, 2001).

Vale destacar que região em questão continua sendo a com menor densidade populacional do país e que as mudanças aqui mencionadas por nós, se deram, principalmente no contexto de cidades que sediam ou sediaram grandes - ou mesmo médios e pequenos - projetos de exploração mineral[1] como é o caso de Pedra Branca do Amapari, por exemplo. 
Esta realidade regional decorreu do processo de expansão física do capital que amplia as formas de aumento da exploração econômica. A Amazônia sempre foi uma região de baixa produtividade econômica e, atualmente, como ao longo da sua história de colonização, tem servido basicamente como produtora de commodities para o mercado mundial. No entanto, onde se estabeleceram ciclos economicamente produtivos, decorrentes da instalação e operação de grandes empreendimentos minerais e energéticos ${ }^{1}$ houve aumento populacional e mudanças na configuração social e espacial das cidades.

Para Singer (1980) e Sampaio (2011), o processo de migração está diretamente relacionado ao desenvolvimento do capitalismo, sobretudo com o processo de industrialização por ele causado. Ele afirma que as principais causas dos fluxos migratórios são justamente as desigualdades regionais provocadas nesses processos de industrialização. Ou seja, o processo de desenvolvimento do capital leva à concentração das atividades produtivas, gerando desigualdades regionais que induzem os processos de migração.

A região, nas últimas décadas, passou por um período de forte intensificação da organização espacial e territorial, especialmente nas primeiras áreas onde foram abertas estradas e ferrovias, onde surgiram novos núcleos urbanos e onde foram e estão sendo operados grandes projetos energéticos e minerais, atividades de garimpagem, de agropecuária extensiva, etc. Estas atividades foram se desenvolvendo na região de acordo com a expansão física do capital, objetivando o aumento da produtividade regional (MENEZES, 2001).

Neste sentido, analisamos este processo na Amazônia como destacado por Leff (2006) e Ferreira e Castro (2009, p. 04) destaca: "o materialismo histórico procura dar conta da estrutura social que converte a natureza em objetos de trabalho, valores de uso naturais capazes de serem incorporados ao processo de produção de riqueza e trabalho".

Desse modo, na Amazônia ocorreram modificações decorrentes - apesar da não total incorporação do seu território aos processos históricos e atuais de colonização 
europeia e norte-americana - das alterações na dinâmica de ocupação territorial da regional. O fenômeno da migração é um efeito claramente visível na região, pois cidades, locais, microrregiões, etc. que abrigam ou abrigaram empreendimentos minerais, receberam um incremento populacional acima da média geral da Amazônia (IBGE, 2010). Pedra Branca, por exemplo, recebeu um incremento populacional equivalente a 9,00\%, acima da média do próprio Estado do Amapá (BARSOSA, 2009).

A disputa mundial pelos recursos naturais da região faz com que a disputa pelo controle do território torne-se crucial no contexto geopolítico da Amazônia. No entanto, este modelo de ocupação regional adotado pelo Estado nacional, ou seja, um modelo predatório explorador, consolidado a partir da década de 70 , contrasta fortemente com a dinâmica populacional, econômica, cultural, política e social da região.

No que tange ao trabalho, foram os ciclos economicamente produtivos, que produziam/produzem para o mercado externo, ou seja, para exportação para o mercado internacional, que foram responsáveis por introduzirem formas de trabalho típicas das sociedades capitalistas e urbanizadas na Amazônia, no entanto, até hoje não dominantes, pois na região prevalecem ainda hoje as relações de trabalho, em certa medida, destoantes das relações de trabalho típicas do mundo do trabalho capitalista, caracterizadas majoritariamente pela informalidade e pelo extrativismo.

A heterogeneidade sociocultural e ambiental constitui uma das maiores características da região amazônica. A própria organização do trabalho na Amazônia apresenta diversidade que não pode ser compreendida apenas sob a lógica do capital. Existem formas peculiares de ocupabilidade que remontam a culturas tradicionais e que se inserem no âmbito das estratégias de sobrevivência dos povos da floresta (TORRES, 2001, p. 01).

Desse modo, importa compreender que as relações de trabalho na Amazônia não podem ser entendidas unicamente pelo prisma do trabalho industrial assalariado, que chega a ser uma categoria relativamente recente na Amazônia brasileira e que ganha notoriedade, principalmente, a partir de meados do século XX (TORRES, 2001).

Antes de tudo, devemos analisar que a economia da Amazônia desde a colonização portuguesa até metade do século $\mathrm{XX}$, foi marcada fortemente pelas atividades 
extrativistas. Os diversos modos econômicos e culturais da região, ou seja, as variadas formas de ocupabilidade existentes devem-se a operação de estratégias, sejam tradicionais ou emergentes, voltadas para a garantia da sobrevivência das populações amazônicas. Pelas estratégias tradicionais entendemos as formas baseadas na manutenção da estrutura social familiar, economicamente, pouco integradas ao mercado. Como emergentes, entendemos justamente aquelas baseadas nas relações de trabalho peculiares das sociedades industriais (TORRES, 2001).

De acordo com Simões (2009), em presença da continuidade das políticas desenvolvimentistas para a região, na qual a base para instalação de novos empreendimentos continua sendo o acesso aos recursos naturais da Amazônia a baixo custo e sem considerar os aspectos sociais, culturais e ambientais da população local, é possível afirmar aquilo que a maioria dos estudos sobre a economia da região já analisaram: a Amazônia é caracterizada, principalmente, por exportar matéria-prima sem qualquer planejamento de diversificação produtiva ou estruturação local.

Desse modo, evidenciamos como o processo de ocupação territorial da região engendra processos de exploração dos recursos naturais atendendo aos interesses da reestruturação produtiva da economia mundial e da expansão física do capital, dirigidas pelo Estado brasileiro, em detrimento dos interesses e das peculiaridades da população local. Como todo processo de expansão física do capital demanda um contingente de força de trabalho para realizar-se, na Amazônia não ocorre de forma diferente, com isso, tornando-se uma região com fatores de atração populacional e consequentemente, sofrendo uma intensificação dos fluxos migratórios em sua direção e modificando a dinâmica das relações de trabalho e socioespaciais da região.

\section{RELAÇÕES DE TRABALHO E MIGRAÇÃO EM PEDRA BRANCA DO AMAPARI: EFEITOS SOCIAIS DA MINERAÇÃO NO MUNICÍPIO}

O município de Pedra Branca do Amapari, criado em 1992, buscando reorganizar o Amapá territorial, política e administrativamente (PORTO; BIANCHETTI, 2005) possuía, até recentemente, determinada irrelevância no cenário econômico e político 
amapaense, pois a cidade era apenas uma pequena urbe do estado sem intensidade em nenhuma atividade econômica.

A partir da descoberta de minas de ouro, PBA passou a ter um atrativo populacional específico, mas vale destacar que a primeira exploração dessas minas não foi industrial, mas sim de forma garimpeira, como afirma Barbosa: "até 2004, a economia do município era movida: pela exploração mineral de ouro, de forma artesanal pelos garimpeiros; pela exploração de madeira, para atender os serviços de manutenção da EFA; e também pela agricultura de subsistência" (BARBOSA, 2001, p. 93).

A partir de 2000, com a consolidação de um ambiente favorável para a exportação de commodities minerais e diante da potencialidade metalogenética do Amapá, houve retorno nos investimentos em pesquisa mineral no estado. Com isso, foram descobertos novos depósitos minerais, onde alguns até já se tornaram empreendimentos concretos, fazendo com que o setor mineral readquirisse lugar de destaque na economia amapaense (OLIVEIRA, 2010).

Eis que nesse cenário amapaense, de investimentos em pesquisas no setor mineral, entram em questão os depósitos de ouro e ferro encontrados no município de Pedra Branca do Amapari. Sobre isso, destacamos:

Ainda em 2005, foi inaugurado o projeto de valorização dos depósitos auríferos de Amapari pela empresa Mineração Pedra Branca do Amapari LTDA. - MPBA. Em quatro anos de operação, a empresa extraiu mais de nove toneladas de ouro (...). No momento, o projeto passa por uma reavaliação das reservas de minério primário, com previsão de retorno de lavra para 2014. Também na região de Amapari, próximo das minas auríferas da MPBA, foram encontrados importantes depósitos de minério de ferro, cujo potencial atraiu o investimento na exploração destes recursos por parte da empresa MMX Mineração e Metálicos (OLIVEIRA, 2010, p. 26).

Atualmente, a exploração do minério de ferro em PBA é realizada, além de Empresas Nacionais e Internacionais, também possuem um montante de empresas terceirizadas que prestam serviços para elas, criando assim, uma rede de empregos diretos e indiretos, gerados pela exploração mineral no município, responsável pelo grande atrativo populacional da cidade nos últimos anos. 
Diante da instalação de empreendimentos minerais na cidade, tem se como consequência a formação de novos núcleos urbanos, como a exemplo do que acontece em toda a região amazônica, onde cidades ao redor de grandes empreendimentos alteram substancialmente sua estrutura sócio-espacial decorrente do aumento populacional desordenado, aspecto comum nesses processos.

Desse modo, o que ocorre em Pedra Branca não é diferente do que acontece nas demais cidades da Amazônia brasileira. Com a efetivação da exploração mineral industrial, alteram-se também a dinâmica das relações de trabalho e a constituição sócio espacial do município. A partir do contexto da instalação de grandes projetos, se desenvolve uma rede de serviços necessária direta e indiretamente à execução destes, que estão diretamente relacionadas ao mundo do trabalho, sobretudo numa região de baixa produtividade econômica como Amazônia e num estado em condição idem, como é o caso do Amapá.

Somente a instalação dos projetos é suficiente para alterar diretamente as relações de trabalho na cidade, pois como representantes do grande capital, as empresas que exploram o minério em PBA, introduzem formas de trabalho típicas das sociedades industriais. Além disso, existem também as consequências de suas instalações; a notícia de que a cidade abriga empreendimentos de exploração mineral torna-se suficiente para a atração de pessoas de outras cidades motivadas, sobretudo, por interesses econômicos, avistando perspectivas de melhorias das condições materiais de existência, graças ao aumento da oferta de emprego e renda, sejam diretamente nas atividades de mineração, sejam como consequência da rede de serviços necessária e gerada pela mesma, como também pela consequência da reestruturação das relações sociais e econômicas da cidade que exigem novos ajustes que também influenciam nas relações de trabalho.

Vale destacar que as mudanças na dinâmica das relações de trabalho não estão somente relacionadas às atividades necessárias a execução da exploração mineral no município. As teorias da migração no Brasil mostram que na sua maioria, os movimentos migratórios, pendulares ou não, são, acima de tudo, motivados por 
interesses econômicos, colocando o trabalho como o cerne dessa relação de migração e economia.

Porém, destaca-se aqui, que a migração possui também características motivacionais diferentes daquilo que é considerado o principal motivo das migrações a nível mundial. Essas características diferem quando se tratam da faixa etária e sexo dos migrantes. O que queremos afirmar é que a migração se dá também motivada por contextos familiares. Homens são, majoritariamente, motivados por interesses econômicos, já mulheres e crianças são motivadas, sobretudo, por motivos familiares (JANNUZZI; OLIVEIRA, 2005).

Nesse sentido, nos importa compreender que os dois motivos estão inteiramente relacionados; os motivos familiares das mulheres e crianças estão associados aos motivos econômicos dos homens. Ou seja, quando se trata da mesma família, as mulheres e crianças, na sua maioria, migram para acompanhar os maridos e pais, respectivamente. Resta também destacar, que os motivos econômicos não perdem a sua centralidade nesta relação e que está diretamente relacionado ao mundo do trabalho (JANNUZZI; OLIVEIRA, 2005).

Consequentemente, isto gera uma cadeia de demandas para serem atendidas, além de diretamente influenciar no desenvolvimento do comércio local. Desse modo, percebe-se que o aumento populacional do município está diretamente relacionado com o período em que se começaram as pesquisas e a efetiva exploração mineral industrial na cidade. Com um intenso fluxo migratório, além do aumento populacional ocorrem também mudanças na configuração urbanística na cidade, conforme destaca Barbosa (2009), a seguir:

Com a instalação das duas empresas mineradoras, o município passa a ser o foco dos diversos segmentos da economia e, com isso a cidade, foi impactada pelo adensamento populacional. O poder público, porém, não adotou as medidas mitigadoras para adequar a área urbana a nova realidade populacional e nem tampouco estruturou a cidade com os equipamentos sociais com vistas a atender o munícipe de Pedra Branca (...) (BARBOSA, 2011, p. 93). 
O binômio mobilidade da população e urbanização é um dos mais dolorosos aspectos do processo de ocupação regional, uma vez que as cidades não tiveram condições de recursos e de tempo para absorver os migrantes (SUDAM, 2011). Pedra Branca, como uma cidade da região amazônica, vivencia também este contexto. O processo migratório a trouxe graves consequências sociais por conta da falta de planejamento urbano que impede que a cidade se constitua como espaço capaz de absorver o incremento populacional e gerar desenvolvimento social, econômico, político e urbano para a sua população.

Além do aumento populacional, PBA passou por uma reestruturação espacial que inclui a criação de novos bairros e ampliação da área urbana da cidade. Além disso, o locus principal de habitação na cidade também mudou, ou seja:

No que diz respeito à distribuição da população por zona de localização, em 2000 , o município era predominantemente rural, pois $65,98 \%$ da sua população estava ocupando a área rural. Entretanto, em 2007, a maior concentração populacional passou a ser urbana $55,69 \%$, seguindo a tendência do estado do Amapá e do Brasil; já no Censo de 2000, apresentavam respectivamente $89,0 \%$ e $81,20 \%$ das pessoas morando em área urbana. O Censo 2010 confirmou esse fato, evidenciando que a população brasileira está mais urbanizada que há 10 anos, com registro de $84,35 \%$ da população vivendo na zona urbana (BARBOSA, 2011, p. 91).

A cidade de Pedra Branca cresce sem nenhum instrumento de regulação da ocupação territorial (BARBOSA, 2011). O município possui apenas 3,9\% dos domicílios particulares com saneamento básico considerado adequado; $67,7 \%$ é considerado semi-adequado e cerca de $28,4 \%$ dos domicílios possuem saneamento completamente inadequado (IBGE, 2010). A coleta de lixo é regular somente em alguns bairros e a limpeza das ruas não ocorre em toda a cidade.

De acordo com Ribeiro e Silva (2010), PBA não possui plano diretor que organize e regule o crescimento urbano no município. $O$ grande crescimento populacional por qual a cidade vem passando nos últimos anos, teve consequências como a falta de infraestrutura urbana, ausência de saneamento básico, ocupação territorial 
desordenada, habitações em condições precárias, dificuldades de mobilidade e má condições de acessibilidade, etc.

Dessa maneira, percebe-se que a alta intensidade do fluxo migratório por qual o município vem passando, decorrente do processo de execução de atividades mineradoras realizadas por indústrias de grande capital que ocasionou o aumento da demanda por mão-de-obra na cidade, geraram impactos sociais, econômicos e urbanos em PBA, de tal modo que foi possível analisar que a cidade não dotava de estrutura político-administrativa para enfrenta-los e nem capacidade técnica de gerencia-los. Ou seja, o crescimento da cidade não veio acompanhado de direção ordenada pelo poder público, acarretando no município os problemas mencionados anteriormente por nós que impactam diretamente na vida da população residente em PBA.

\section{ANÁLISE DOS DADOS DA PESQUISA DE CAMPO}

Este novo momento econômico, político e social por qual passa a cidade de PBA são reflexos das novas relações estabelecidas no município decorrentes do desencadeamento da exploração de minério. Desde o início, partimos do ponto de vista de que o processo em curso na cidade faz parte de um processo regional de ocupação e exploração da Amazônia relacionado ao processo internacional de colonização da região, dirigida pelo Estado nacional, atendendo a interesses do capital privado. Como consequências, temos o desenvolvimento de novas relações de trabalho e um aumento populacional influenciado pela demanda de força de trabalho gerada nesses processos.

A pesquisa de campo realizada por nós no município em questão foi importante à medida que serviu para nos subsidiar de dados concretos sobre a realidade da cidade e nos fazer desenvolvermos uma melhor compreensão sobre os impactos socioeconômicos, políticos e ambientais deste processo corrente em PBA. De tal modo, ela também serviu para corroborar a hipótese de trabalho levantada por nós ainda no início da pesquisa, de que em contextos de empreendimentos minerais além 
do aumento do fluxo migratório alteram-se também a dinâmica das relações de trabalho, utilizando esta categoria teórica na realidade do município por nós analisado.

Na pesquisa realizada por nós foi possível ainda perceber que, apesar do grande atrativo populacional e do estabelecimento de relações de trabalho comuns em sociedades industrializadas, prevalecem ainda na cidade as relações de trabalho informais. Entretanto, apesar das relações informais ainda serem a mais comuns, não há uma disparidade tão grande entre o nível de pessoas que trabalham de carteira assinada ou não, ou até mesmo aquelas que possuem vínculo de trabalho formal, mas não em regime de CLT.

Do universo de trabalhadores entrevistados por nós, $55,88 \%$ declararam não trabalhar de carteira de assinada, enquanto que os que declaram que exercem algum tipo de trabalho com a carteira assinada representaram 44, 11\%. É importante dizer que todos aqueles que exercem atividades nas áreas de mineração, declararam possuírem relações formais de trabalho estabelecidas, algo típico da política trabalhista de grandes empresas baseadas no controle, mais amplo possível, de riscos.

No que tange ao processo de migração na cidade, observamos um acentuado crescimento populacional desde o momento da implantação da primeira empresa de minério, destinada a explorar minas de ouro no município. Desse modo, percebemos que "as migrações internas são sempre historicamente condicionadas, sendo o resultado de um processo global de mudança, do qual elas não devem ser separadas" (SINGER, 1980, p. 217).

A pesquisa de campo nos apontou que da população residente no município, apenas $8,82 \%$ são naturais de PBA, a sua maioria, $91,17 \%$, é oriunda de outras cidades ou estados. Portanto, demonstrando que a cidade, neste contexto de operação de grandes empreendimentos minerais é, naturalmente, um local de atração populacional. Sobre isso, Sampaio, ao analisar o que Singer abordou sobre migração, destaca: 
Se, por um lado, existem aquelas regiões cuja população emigra, por outro lado, as regiões que recebem esta população apresentam o que ficou chamado de fatores de atração. O fator de atração mais importante é a demanda por força de trabalho derivado das atividades industriais e dos serviços públicos, privados ou autônomos. Essa demanda é uma função do tamanho e da composição do produto gerado pela economia urbana (SAMPAIO, 2011, p. 63).

Vale destacar que de acordo com o IBGE (2010), mesmo com um aumento parcial da população do município, foi a partir de 2007 que a cidade passou a ter uma intensificação no que se refere ao seu crescimento populacional, período que coincide com o processo de intensificação da exploração mineral em PBA.

$\mathrm{Na}$ figura 2, demonstramos a intensidade desse processo vivenciado na cidade. A grande maioria da população é oriunda de outras cidades e da sua maioria da região Norte, evidenciando a atualidade dos processos de migração interna na Amazônia, engendrados pelos processos de ocupação territorial visando a exploração dos recursos naturais da região, neste caso aqui, da cidade de Pedra Branca do Amapari.

Figura 2: População migrante e população natural de PBA.

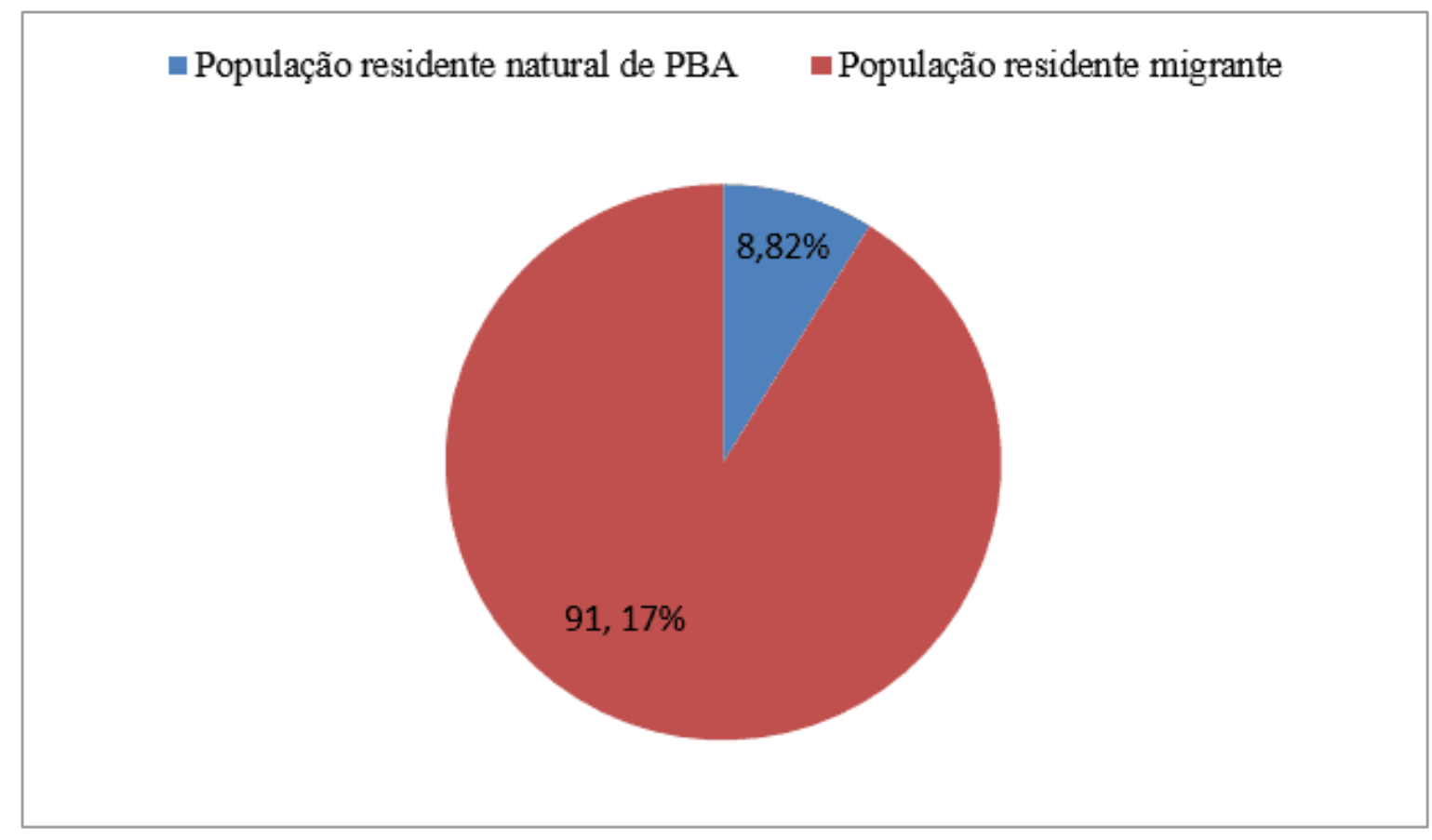

Fonte: Pesquisa de Campo. 
Importa-nos mostrar também que destes $91,17 \%$ de migrantes, $80,6 \%$ é da própria região Norte. Ao passo que isto nos remete aos processos de migração interna na própria Amazônia. Os estados do Pará e Amapá são os locais da onde mais identificamos pessoas. Desses $80,6 \%$, os dois estados representaram cerca de $48 \%$ cada da população não natural de PBA. Aqueles que são oriundos de outros do estado do Norte representaram apenas $4 \%$.

O Nordeste foi a segunda região de onde mais identificamos migrantes. De $91,17 \%$ em PBA, 16,12\% são oriundos desta parte do Brasil. Quando estratificados por estados, os dados da pesquisa mostram que a maioria são oriundas do estado do Maranhão, que sozinho chegou a representar $60 \%$ da migração advinda desta região. Apesar de identificarmos pessoas de outras regiões do país, somente essas duas regiões totalizaram $96,77 \%$ da população migrante da cidade, sendo apenas $3,22 \%$ vindas de outras regiões do Brasil. (Figura 3).

Figura 3: População migrante em PBA oriunda da região Norte.

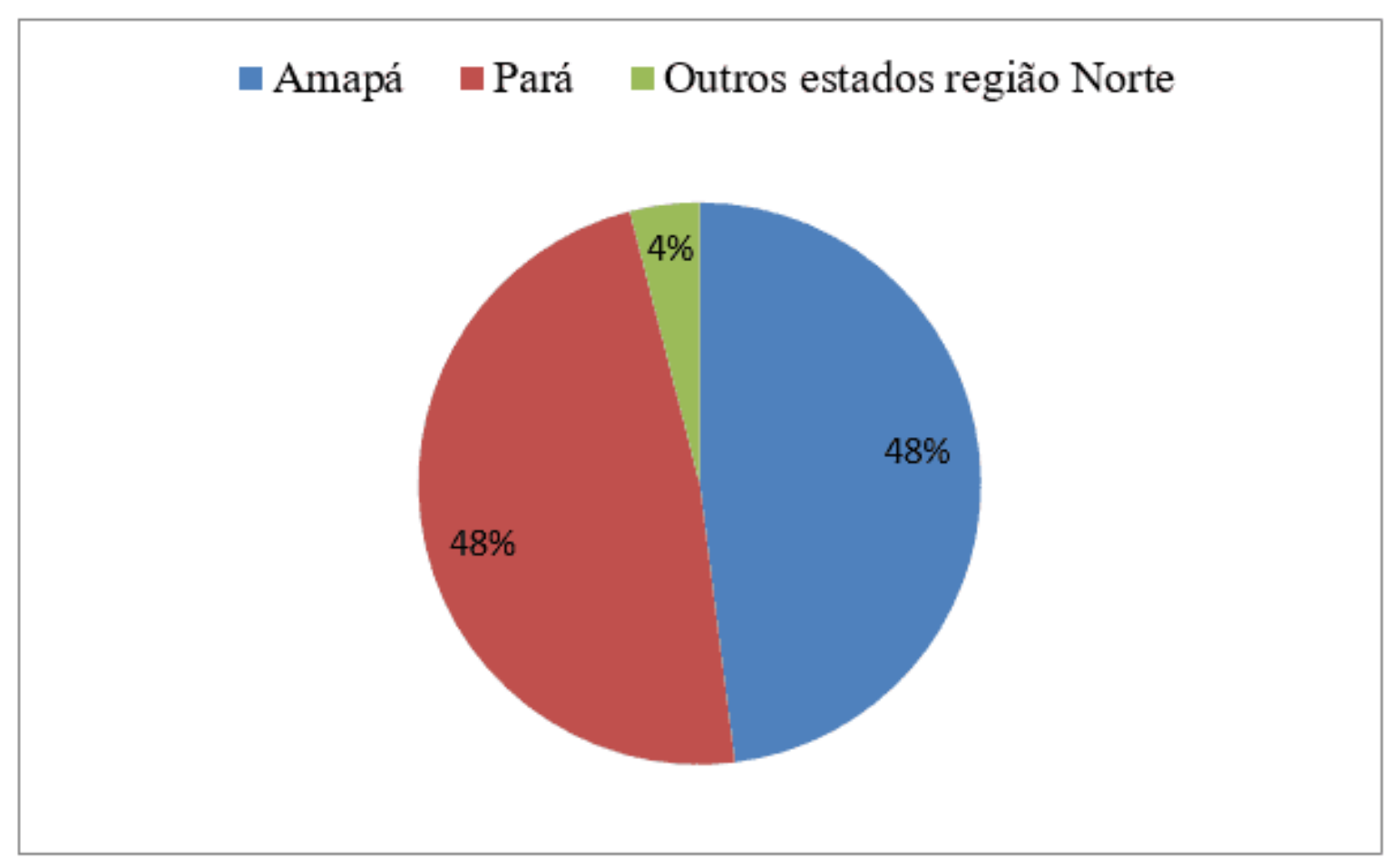

Fonte: Pesquisa de Campo. 
A pesquisa perguntou também aos migrantes qual o principal motivo do deslocamento para PBA. Dos $91,17 \%$ oriundos de outras cidades, $93,54 \%$ afirmaram que o principal motivo está relacionado ao trabalho, como a busca e a maior oferta de emprego, ambiente mais favorável para o comércio e a busca por melhores condições de vida, relacionadas às maiores oportunidades de trabalho.

Este ponto, o que mais nos chamou a atenção, revela a base dos deslocamentos populacionais no Brasil: a questão econômica. Por mais que o fenômeno da migração possua características peculiares e multifacetadas, o ponto nevrálgico dos deslocamentos populacionais ainda continua sendo a busca por melhores condições materiais de existência. Como afirma Singer (1980) e Oliveira, (2011, p. 13), "no lugar de destino estariam os fatores de atração, que orientariam os fluxos e os locais para onde se destinariam. O principal fator de atração seria a demanda por força de trabalho, também entendida como "oportunidades econômicas".

Quando perguntamos sobre o fato da pretensão de voltar para a cidade de origem, $54,83 \%$ afirmaram que não tem nenhuma intenção de voltar. Já os que responderam que pensam nesta possibilidade representam $38,70 \%$ e os que opinaram afirmando que talvez voltem representaram $6,45 \%$. Vale destacar que dos $54,83 \%$ que afirmaram que não pretendem voltar, $88,235 \%$ disseram que os principais motivos estão relacionados a oferta de emprego e as condições de vida no lugar de origem. Dos que disseram que pretendem voltar, metade afirmou que a família é o principal motivo do retorno.

No que se refere a rede de saúde pública do município de PBA, a cidade possui uma Unidade Mista e uma Unidade Básica de atendimento, ambas, de baixa complexidade, o que obriga quem necessitar de atendimento de média e alta complexidade, descolocar-se para Macapá, a capital do estado. Ademais, identificamos também o funcionamento daquele que representa um dos maiores avanços do Sistema Único de Saúde - SUS, mas possui enormes dificuldades estruturais de funcionamento, o Programa Saúde da Família 
No que tange ao saneamento básico, 67, 64\% afirmaram não possuir água encanada através de abastecimento público. De acordo com eles, o abastecimento domiciliar de água é feito através de poço amazonas ou artesiano. Já os que afirmaram possuir água encanada representaram 32,35\%, no entanto, afirmaram não ser tratada. Nesta situação, ocorre que a água encanada a qual os moradores se referiram, trata-se da água advinda do chamado "balneário". A instalação foi viabilizada pelo poder público, porém os próprios funcionários da Prefeitura Municipal de Pedra Branca do Amapari declararam que ela não possui tratamento, sendo imprópria para o consumo.

No que se refere a coleta de lixo, $82,35 \%$ dos entrevistados declararam que ela ocorre regularmente. Nesses casos, em alguns bairros como o Centro, por exemplo, ela se dá diariamente, mas em outros, ocorre 3 vezes por semana. Já os que afirmaram que a coleta não ocorre regularmente totalizaram 11,76\%. É importante ressaltar que para níveis de analise, consideramos a coleta realizada menos de 3 vezes por semana. Em média, a maioria afirmou que a coleta, nesses casos ocorre cerca de 1 à 2 vezes por semana. Os que afirmaram que a coleta não ocorre representaram $5,88 \%$ dos entrevistados. Esses, afirmaram que a coleta não ocorre porque o bairro não é reconhecido na prefeitura e, portanto, inexistente oficialmente.

Por fim, resta-nos destacar uma questão importante: os bairros em que a coleta ocorre de forma irregular ou não acontece, ficam em territórios afastados do centro da cidade e fazem parte do processo de reestruturação espacial do município, ocasionado pelo grande crescimento populacional e desordenado. Demonstrando assim que as relações urbanas na cidade são reflexos do desenvolvimento sócio espacial desigual engendrado pelos processos de ocupação territorial e do desenvolvimento produtivo da região.

A partir desses dados, foi possível analisar com mais precisão os efeitos sociais que a atividade mineradora gerou no município. A demanda por força de trabalho, consequentemente, ocasionou um grande crescimento populacional desordenado que, por sua vez, devido à falta de planejamento urbano municipal, agravou problemas já existentes como a falta de saneamento básico, a ocupação desordenada do solo e a ineficiência dos serviços públicos. 


\section{CONSIDERAÇÕES FINAIS}

O processo histórico de colonização da Amazônia seguiu diferentes modelos econômicos de acordo com os momentos históricos e com o processo de reestruturação produtiva do capital. Em escala mundial, a região possui importante papel para o mercado internacional e todo o processo de exploração dirigido atualmente na região serve para cumpri-lo.

Desse modo, o atual modelo observado exploratório da região obedece aos interesses do capital privado, gerando processos de ocupabilidade que priorizam o desenvolvimento do capital em contraste com as relações sociais, culturais e ambientais estabelecidas nas formas de ocupação induzidas pela população da região. Desse modo, analisamos o processo em curso em PBA como parte integrante deste processo de exploração e ocupação regional e, que como tal, sofre as consequências de um processo dirigido que prioriza formas exógenas de desenvolvimento regional.

Assim, percebemos que a exploração mineral realizada em Pedra Branca do Amapari está relacionada ao contexto da instalação de grandes projetos minerais, energéticos e metalúrgicos na região, que, por sua vez, estão associados ao processo regional acima citado. É importante destacar também que o direito à exploração de qualquer reserva mineral é concedido pelo Estado, revelando assim que a forma, como hoje são garantidas as licenças às empresas de exploração de minérios obedecem à lógica de favorecimento do capital privado.

O alto índice de aumento populacional revelou que a demanda por força de trabalho continua sendo a base dos deslocamentos populacionais na Amazônia e que migração e relações de trabalho são conceitos intrinsicamente ligados à medida que ambos fazem parte do processo de expansão física do capital e de reestruturação produtiva da economia. Pedra Branca do Amapari, a partir do momento que passou a demandar maior força de trabalho para atender aos objetivos das atividades de exploração de minério na cidade, tornou-se local de atração populacional, sendo alvo de migrantes de todas as regiões do país. 
A exploração mineral operada no município trouxe à cidade consequências sociais, econômicas, políticas e urbanas que foram responsáveis por mudanças nas configurações sociais e espaciais da cidade. Dessa forma, percebemos que os impactos da exploração mineral vão além do aumento da arrecadação financeira e da atração populacional. Os ganhos econômicos, nesses casos, se não bem aproveitados e utilizados para dirigir processos planejados de urbanização e de geração de qualidade de vida, tornam-se sem função social e incapazes de atender as demandas sociais da população.

\section{REFERÊNCIAS}

BARBOSA, R. G. Os efeitos da mineração na arrecadação e no processo de urbanização do município de Pedra Branca do Amapari. Dissertação de Mestrado, Universidade Federal do Amapá - UNIFAP, 2011.

Impactos da compensação financeira sobre a exploração mineral no processo de urbanização do município de Pedra Branca do Amapari - 2004/2008. PRACS: Revista Eletrônica de Humanidades do Curso de Ciências Sociais da UNIFAP, № 2. Dez. 2009.

BECKER, B. K. Revisão das políticas de ocupação da Amazônia: é possível identificar modelos para projetar cenários? Modelos e cenários para a Amazônia: o papel da ciência. Parcerias estratégicas - Número 12 - Setembro, 2001.

BIANCHETTI, A.; PORTO, J. L. R. Dinâmicas urbanas amapaenses: Conflitos e perspectivas de um estado em construção. In: Congresso Internacional em Planejamento e Gestão Ambiental, 2005, Brasília. Congresso Internacional em Planejamento e Gestão Ambiental. Brasília, 2005.

FERNANDES, J. G. S. "Narrativas migrantes e a constituição da cultura popular na Amazônia". IN: Revista Ágora, v. 12, n.1. Santa Cruz do Sul: EDUNISC, 2006.

FERREIRA, K. J.; CASTRO, C. P. Amazônia: exploração colonial no século XXI. Junho, 2009. 
IBGE. Censo demográfico de 2000. Disponível em: <www.ibge.gov.br>. Acesso em: 01 de julho de 2013.

Censo demográfico de 2010. Disponível em:<www.ibge.gov.br>. Acesso em 02 de julho de 2013.

JANNUZZI, P. M.; OLIVEIRA, K. F. Motivos para migração no Brasil e retorno ao Nordeste: padrões etários, por sexo e origem/destino. São Paulo, Perspectivas, vol.19 no. 4. São Paulo, Outubro/Dezembro, 2005.

LEFF, H. Racionalidade ambiental: a reapropriação social da natureza. Rio de Janeiro: Civilização Brasileira, 2006.

MENEZES, M. L. P. A crise do estado de bem-estar e a caracterização de processos territoriais da migração no Brasil. Revista Electrónica de Geografía y Ciencias Sociales. Universidad de Barcelona, № 94 (85), 1 de agosto de 2001.

MONTEIRO, M. A. Meio século de mineração industrial na Amazônia e suas implicações para o desenvolvimento regional. Coleção Estudos Avançados, Ed. 19 (53), 2005.

OLIVEIRA, L. A. P.; OLIVEIRA, A. T. R. Reflexões sobre os deslocamentos populacionais no Brasil. Coleção Estudos e análises: informação demográfica e sócio econômica, № 1, IBGE. Rio de Janeiro, 2011.

OLIVEIRA, M. J. Diagnóstico do setor mineral do Amapá. IEPA, Macapá, 2010.

RIBEIRO, A. C.; SILVA, R. P. Aspectos institucionais e urbanos para o desenvolvimento local do município de Pedra Branca do Amapari/Amapá. PRACS: Revista de Humanidades do Curso de Ciências Sociais da UNIFAP Macapá, n. 3, p. 19-32, Dez. 2010.

SAMPAIO, D. P. Contribuições de Paul Singer para o entendimento da "questão urbana" no Brasil. Leituras de Economia Política, Campinas, (19), p. 51-67, dez. 2011. 
SILVA, M. A. M. "Contribuições metodológicas para a análise de migrações". IN: DEMARTINI, Z. B.; TRUZZI, O. M. Estudos migratórios: perspectivas metodológicas. São Carlos: EdUFSCAR, 2005.

SIMOES, H. C. G. Q. A História e os efeitos sociais da mineração no estado do Amapá. PRACS: Revista Eletrônica de Humanidades do Curso de Ciências Sociais da UNIFAP, № 2. Dez. 2009.

SINGER, P. Migrações internas: considerações teóricas sobre seu estudo. In: MOURA, H. A. de (Coord.). Migração interna: textos selecionados. Fortaleza: Banco do Nordeste do Brasil - BNB, Escritório Técnico de Estudos Econômicos do Nordeste, 1980. t. 1, p.211-244. (Estudos econômicos e sociais, 4).

SUDAM. Demografia. 2011.

TORRES, I. C. Amazônia: noções de trabalho, trabalhadores e relações com a nação, 2001.

\section{APÊNDICE - REFERÊNCIA DE NOTA DE RODAPÉ}

1. Na verdade, grandes projetos não somente do setor mineral, mas também metalúrgico, energético, agropecuário, etc.

Enviado: Dezembro, 2019.

Aprovado: Dezembro, 2019. 